\title{
Glulam columns made of European beech timber: compressive strength and stiffness parallel to the grain, buckling resistance and adaptation of the effective-length method according to Eurocode 5
}

\author{
Thomas Ehrhart $(\mathbb{D} \cdot$ René Steiger $(\mathbb{D} \cdot$ Pedro Palma $\mathbb{B}$ - Ernst Gehri \\ Andrea Frangi $(\mathbb{D}$
}

Received: 30 October 2019/Accepted: 1 July 2020/Published online: 14 July 2020

(C) The Author(s) 2020

\begin{abstract}
This article presents experimental and numerical investigations on the buckling behaviour of glulam columns made of European beech (Fagus sylvatica L.) timber and a design proposal. First, the compressive strength parallel to the grain $\left(f_{\mathrm{c}, 0}\right)$ and the modulus of elasticity parallel to the grain $\left(E_{\mathrm{c}, 0}\right)$ were experimentally determined in tests on stocky columns (slenderness ratio $\lambda=12.5$ ) of strength classes GL 40h, GL 48h, and GL 55h. Subsequent experimental buckling tests on slender columns with buckling lengths of $2.40 \mathrm{~m}(\lambda=41.5)$ and $3.60 \mathrm{~m}(\lambda=62.3)$ allowed investigating the buckling behaviour and quantifying the influence of the buckling length on the buckling resistance. Applicability of the effectivelength method, which is the design method for columns in Eurocode 5 (EN 1995-1-1: Design of
\end{abstract}

T. Ehrhart · A. Frangi

Institute of Structural Engineering, ETH Zürich,

Stefano-Franscini-Platz 5, 8093 Zurich, Switzerland

R. Steiger $(\bowtie) \cdot$ P. Palma

Structural Engineering Research Laboratory, Empa, Swiss

Federal Laboratories for Materials Science and

Technology, Ueberlandstrasse 129, 8600 Dübendorf,

Switzerland

e-mail: rene.steiger@empa.ch

E. Gehri

Prof. Emeritus, ETH Zürich, 8803 Rüschlikon,

Switzerland timber structures - Part 1-1: General - Common rules and rules for buildings. European Committee for Standardization, Brussels, 2010), was evaluated and a proposal for input parameters valid for columns made of European beech glulam is made. Numerical simulations revealed buckling resistances very close to the experimental results, confirming the proposed critical relative slenderness ratio $\lambda_{\text {rel }, 0}=0.25$ and the fitted straightness factor $\beta_{\mathrm{c}}=0.25$. In addition, the numerical simulations allowed for an extension of the scope of the investigations.

Keywords Compressive strength - Buckling resistance $\cdot$ Glulam $\cdot$ European beech wood $\cdot$ Eurocode $5 \cdot$ Effective-length method (ELM)

\section{Introduction}

European beech (Fagus sylvatica L.) is a timber species with a very high share in the forest hardwoods stock in many central European countries. The use of this species for construction purposes has increasingly been the subject of investigations in recent years because of its availability and its strength and stiffness properties. Regarding its use as a structural material, namely in structural columns, a particularly relevant aspect which has not been studied is the buckling resistance. 
In Eurocode 5 (EC5) [1], the design method for columns prone to buckling is based on the effectivelength method (ELM). The design formula assumes that the compressive strength is reduced due to the effect of instability-related factors (Eqs. 11-14). The general procedure is identical to the design of steel columns [2]. The straightness factor $\beta_{\mathrm{c}}=0.10$ and the critical relative slenderness $\lambda_{\text {rel }, 0}=0.30$ had been determined in investigations on softwood columns by Blaß $[3,4]$.

Experimental full-scale buckling tests on softwood glulam columns and accompanying numerical simulations by Theiler [5] have indicated that design according to Eurocode 5 [1] may lead to an overestimation of the actual buckling resistance, especially for slenderness ratios in the range of $50 \leq \lambda \leq 100$. However, in the experiments conducted by Theiler [5], eccentricities exceeding the limits defined in Eurocode 5 [1] were realised. Similarly, Estévez Cimadevilla et al. [6] found that a straightness factor of $\beta_{\mathrm{c}}=0.30$ (instead of 0.10) would lead to a much better fit of the ELM design with their results of full-scale buckling tests on softwood glulam columns. Again, the authors argued that the connection used in the tests might have caused additional eccentricities, leading to a reduction of the buckling resistance. Fleming and Ramage [7] conducted full-scale buckling tests on stress-laminated columns with slenderness ratios of $\lambda=44$ and 53. The authors reported that the mean buckling resistance resulting from the tests was at $(\lambda=44)$ or even significantly below $(\lambda=53)$ the $5 \%$-fractile values predicted by the design equations included in Eurocode 5 [1].

For European beech glulam, the ratio between compressive strength and modulus of elasticity (MOE) parallel to the grain is about $1 / 250[8,9]$, whereas for softwood glulam, ratios between $1 / 370$ and $1 / 420$ have been reported [3]. It was therefore deemed necessary to assess the applicability of the current Eurocode 5 [1] design methods to beech glulam columns. In this article, experimental and numerical investigations on the compressive strength parallel to the grain and the buckling resistance of beech glulam columns are presented and adapted design buckling curves are determined.

\section{Materials and methods}

\subsection{Material}

Swiss-grown European beech boards were used for the production of the glulam columns. The boards were strength graded into tensile strength classes T33 (to produce GL 40h), T42 (to produce GL 48h), and T50 (to produce GL 55h), applying the strength grading rules developed by Ehrhart et al. [10]. The laminations were bonded using a one-component polyurethane adhesive and a primer, following the findings of investigations on appropriate bonding procedures conducted by Henkel Engineered Wood Adhesives and $\mathrm{BFH}$ Biel [11]. The lamination thickness was 25 $\mathrm{mm}$ and the wood moisture content was $\omega=8 \pm 2 \%$, which represents the climatic conditions of the indoor use of beech glulam.

\subsection{Experiments}

\subsubsection{Compression tests on stocky columns}

Stocky columns, i.e., columns not prone to buckling failures, were tested in compression according to EN 408 [12] (Fig. 1), to determine the compressive strength parallel to the grain $\left(f_{\mathrm{c}, 0}\right)$ and the compressive MOE parallel to the grain $\left(E_{\mathrm{c}, 0}\right)$. Columns with homogeneous cross-section layups, i.e., with laminations of identical strength class, of the glulam strength classes GL 40h, GL 48h, and GL 55h were investigated. The widths of the specimens with square crosssections were $b=150,200$ and $280 \mathrm{~mm}$, the length of the columns was $L=6 \times b$ and thus $L=900,1200$ and $1680 \mathrm{~mm}$. For each test series, i.e., for each GLstrength class and cross-section width, seven specimens were tested. An overview on the number and the geometrical properties of the tested stocky columns is presented in Table 1.

Due to the support conditions prescribed by EN 408 [12] (loading heads locked against rotation or angular movement during the test), the buckling length was $L_{\mathrm{c}}=0.6 \times L[13]$. This resulted in a slenderness ratio of $\lambda=12.5$ according to Eq. 1 , with $k$ being the least radius of gyration, $I$ being the second moment of area, and $A$ being the area of the cross-section. 


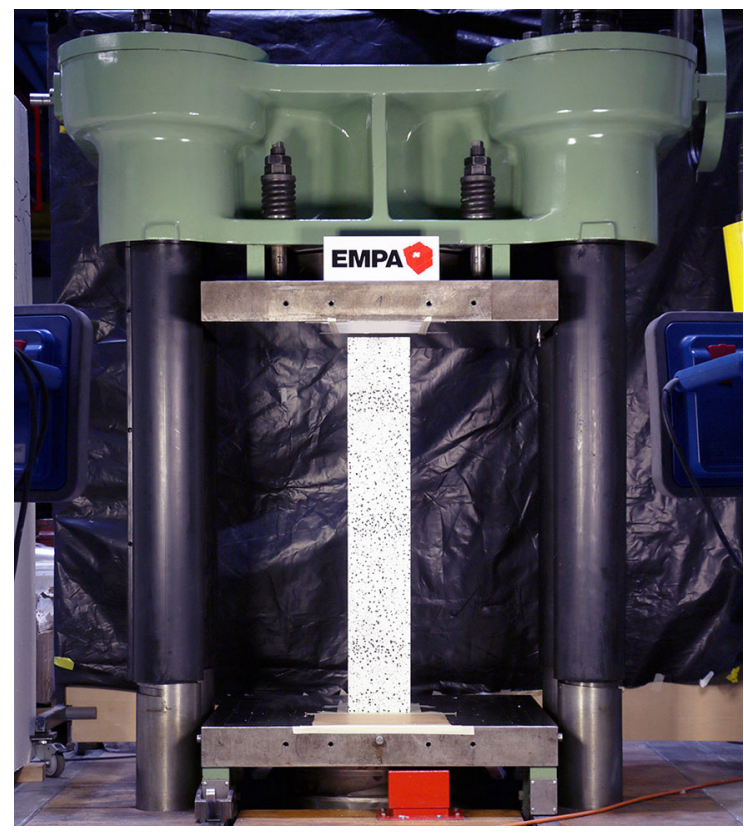

Fig. 1 Axial compression test according to EN 408 [12] of a stocky column with a length $L$ of $900 \mathrm{~mm}$ (buckling length $\left.L_{\mathrm{c}}=0.6 \times L[13]\right)$

$\lambda=\frac{L_{\mathrm{c}}}{k}=\frac{0.6 \cdot L}{\sqrt{\frac{I}{A}}}=\cdots=\frac{0.6 \cdot 6 \cdot b}{\frac{b}{\sqrt{12}}} \approx 12.5$

A compression test machine (Fig. 1) with a capacity of $5000 \mathrm{kN}$ was used for the tests. The force was applied displacement controlled, at a constant displacement rate of $0.025 \mathrm{~mm} / \mathrm{s}$. The specimen was unloaded after the force had dropped to around $80 \%$ of the maximum test force.

\subsubsection{Buckling tests on slender columns}

Slender columns of strength classes GL 40h and GL $48 \mathrm{~h}$ were tested in axial compression (Fig. 2a). The width of the specimens with square cross-sections was $b=200 \mathrm{~mm}$. The buckling lengths of the columns, consisting of the specimen's length and two times the distance between the front end of the column and the centre of the hinged support (Fig. 2b), were $L_{\mathrm{c}}=12 \times$ $b(2400 \mathrm{~mm})$ and $L_{\mathrm{c}}=18 \times b(3600 \mathrm{~mm})$, resulting in slenderness ratios of $\lambda=41.5$ and $\lambda=62.3$, respectively (Eq. 1).

An overview on the number and the geometrical properties of the tested slender columns is presented in Table 1.

Axial displacements were measured over a length of $3 \times b=600 \mathrm{~mm}$ on all four sides of the columns. Lateral deflections at different heights were measured by means of three displacement transducers mounted on an aluminium bar (Fig. 2c). Loading was applied under displacement control at a constant displacement rate of $0.025 \mathrm{~mm} / \mathrm{s}$. The force was applied with an initial eccentricity of $6.3 \pm 0.3 \mathrm{~mm}$ to the longitudinal axis of the columns, which corresponds to relative eccentricities of $e=1 / 380$ (for $L_{\mathrm{c}}=2400 \mathrm{~mm}$ ) and $e=1 / 570$ (for $L_{\mathrm{c}}=3600 \mathrm{~mm}$ ).

The eccentricity of the applied force was in the direction parallel to the glue lines, so that buckling would occur with the laminations in edgewise bending, involving a homogenisation effect and reducing the influence of weak sections in the outermost laminations.

For glulam columns prone to lateral instability, Eurocode 5 [1] specifies that the deviation from straightness measured midway between the supports
Table 1 Compressive strength $\left(f_{\mathrm{c}, 0}\right)$ and compressive MOE parallel to the grain $\left(E_{\mathrm{c}, 0}\right)$ of the stocky $(\lambda=12.5)$ and slender columns $(\lambda=41.5$ and 62.3). The moisture content of all specimens was $\omega=8 \pm 2 \%$

$n$ indicates the number of specimens per series

\begin{tabular}{lllllllllll}
\hline $\mathrm{GL}$ & $\begin{array}{l}b \\
(\mathrm{~mm})\end{array}$ & $\begin{array}{l}L_{\mathrm{c}} \\
(\mathrm{m})\end{array}$ & $\begin{array}{l}\lambda \\
(-)\end{array}$ & $\begin{array}{l}n \\
(-)\end{array}$ & $\begin{array}{l}f_{\mathrm{c}, 0, \text { mean }} \\
(\mathrm{MPa})\end{array}$ & $\begin{array}{l}f_{\mathrm{c}, 0,05} \\
(\mathrm{MPa})\end{array}$ & $\begin{array}{l}\mathrm{cov} \\
(-)\end{array}$ & $\begin{array}{l}E_{\mathrm{c}, 0, \text { mean }} \\
(\mathrm{MPa})\end{array}$ & $\begin{array}{l}E_{\mathrm{c}, 0,05} \\
(\mathrm{MPa})\end{array}$ & $\begin{array}{l}\mathrm{cov} \\
(-)\end{array}$ \\
\hline $40 \mathrm{~h}$ & 200 & 0.72 & 12.5 & 7 & 60.4 & 59.7 & 0.01 & 15,100 & 14,400 & 0.03 \\
$48 \mathrm{~h}$ & 150 & 0.54 & 12.5 & 7 & 59.9 & 56.4 & 0.04 & 15,600 & 14,600 & 0.04 \\
$48 \mathrm{~h}$ & 200 & 0.72 & 12.5 & 7 & 63.8 & 62.5 & 0.01 & 16,000 & 15,400 & 0.02 \\
$48 \mathrm{~h}$ & 280 & 1.01 & 12.5 & 7 & 58.2 & 55.9 & 0.02 & 15,500 & 14,800 & 0.03 \\
$55 \mathrm{~h}$ & 200 & 0.72 & 12.5 & 7 & 65.8 & 63.7 & 0.02 & 17,000 & 16,700 & 0.01 \\
$40 \mathrm{~h}$ & 200 & 2.40 & 41.5 & 3 & 43.2 & - & - & 15,000 & - & - \\
$48 \mathrm{~h}$ & 200 & 2.40 & 41.5 & 5 & 45.3 & 44.2 & 0.01 & 16,500 & 16,200 & 0.01 \\
$40 \mathrm{~h}$ & 200 & 3.60 & 62.3 & 3 & 28.8 & - & - & 14,800 & - & - \\
$48 \mathrm{~h}$ & 200 & 3.60 & 62.3 & 5 & 30.5 & 29.7 & 0.02 & 16,300 & 15,800 & 0.02 \\
\hline
\end{tabular}



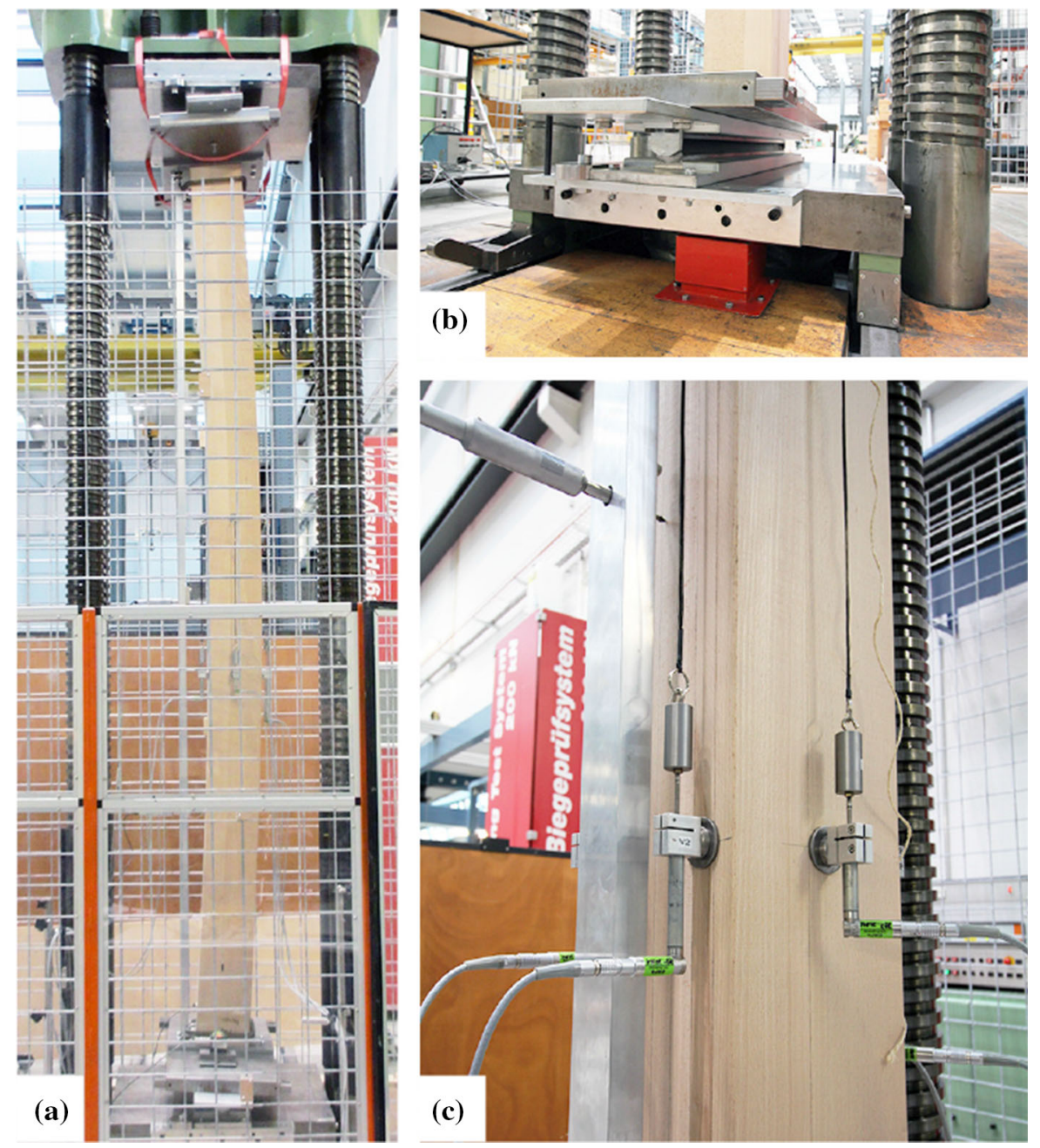

Fig. 2 Buckling test: a buckling of a column with a slenderness ratio of $\lambda=62.3$; $\mathbf{b}$ uniaxial pinned supports were used. The distance between the front ends of the columns and the centre of

should be limited to $1 / 500$ times the length of the column.

\subsection{Numerical simulations}

Additionally to the experimental investigations, numerical simulations of the buckling resistance of beech glulam columns were conducted. Investigations by Blaß [3, 4], Theiler et al. [5, 14] and Frangi et al. [15] have shown that appropriate numerical models can complement experimental tests and contribute to a better understanding of the buckling behaviour of columns. the hinged support was $115 \mathrm{~mm}$; c vertical and lateral deformations were measured by means of LVDTs

These authors applied strain-based models, involving the constitutive model developed by Glos [16] to account for the plastic behaviour of wood in compression parallel to the grain. For the numerical simulations presented in this paper, the code developed by Theiler [5] was adapted to consider a lengthdependent eccentricity of $e=L / 500$ and to use the constitutive model developed by Glos et al. [17] for beech wood (Eqs. 2-6). As mentioned before, $L / 500$ corresponds to the maximum allowed deviation from straightness for glulam according to Eurocode 5 [1].

According to Glos et al. [17], the stress-strain curve may be described by means of Eq. 2. The corresponding stress-strain diagram is presented in Fig. 3. 


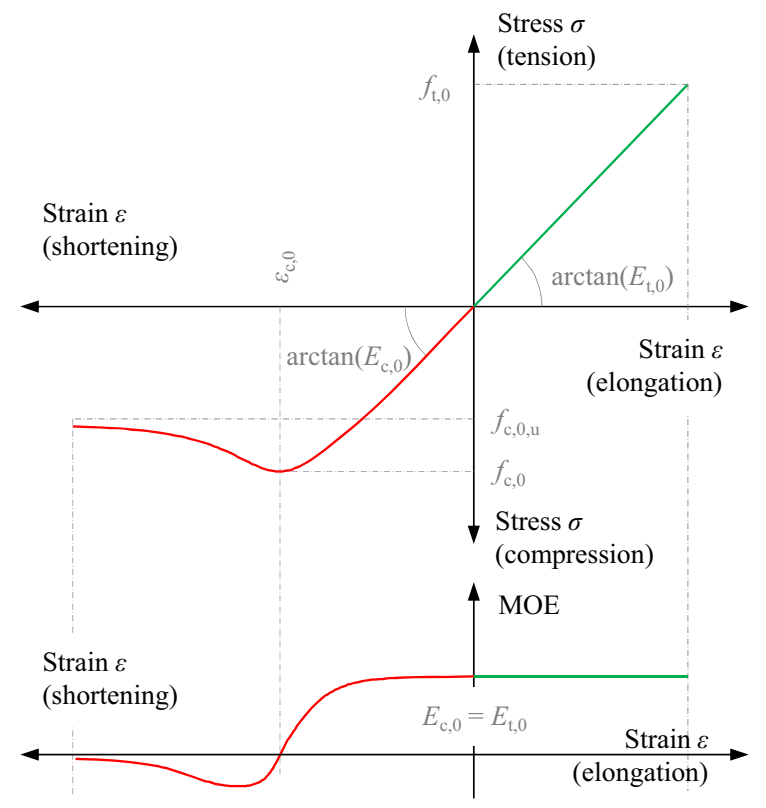

Fig. 3 Stress-strain diagram according to the the constitutive model developed by Glos [16]

$$
\sigma=\frac{\epsilon+k_{1} \cdot \epsilon^{4}}{k_{2}+k_{3} \cdot \epsilon+k_{4} \cdot \epsilon^{4}}
$$

The coefficients $k_{\mathrm{i}}$ are calculated using Eqs. 3-6, taking into account the compressive strength $\left(f_{\mathrm{c}, 0}\right)$ and the strain at failure $\left(\epsilon_{\mathrm{c}, 0}\right)$, the asymptotic residual compressive strength $\left(f_{\mathrm{c}, 0, \mathrm{u}}\right)$ and the compressive $\operatorname{MOE}\left(E_{\mathrm{c}, 0}\right)$ parallel to the grain.

$$
\begin{aligned}
& k_{1}=\frac{f_{\mathrm{c}, 0, \mathrm{u}}}{3 \cdot E_{\mathrm{c}, 0} \cdot \epsilon_{\mathrm{c}, 0}^{4} \cdot\left(1-\frac{f_{\mathrm{c}, 0 \mathrm{u}}}{f_{\mathrm{c}, 0}}\right)} \\
& k_{2}=\frac{1}{E_{\mathrm{c}, 0}} \\
& k_{3}=\frac{1}{f_{\mathrm{c}, 0}}-\frac{4}{3 \cdot E_{\mathrm{c}, 0} \cdot \epsilon_{\mathrm{c}, 0}} \\
& k_{4}=\frac{1}{3 \cdot E_{\mathrm{c}, 0} \cdot \epsilon_{\mathrm{c}, 0}^{4} \cdot\left(1-\frac{f_{\mathrm{c}, 0, \mathrm{u}}}{f_{\mathrm{c}, 0}}\right)}
\end{aligned}
$$

Following O'Halloran [18], the parameter $\beta_{\epsilon}$, which describes the ratio between the total strain when reaching the compressive strength and the elastic strain, is assumed to be 1.25 (Eq. 7). $\epsilon_{\mathrm{c}, 0}=\beta_{\epsilon} \cdot \frac{f_{\mathrm{c}, 0}}{E_{\mathrm{c}, 0}}=1.25 \cdot \frac{f_{\mathrm{c}, 0}}{E_{\mathrm{c}, 0}}$

The parameter $\beta_{\mathrm{f}}$ for the calculation of $f_{\mathrm{c}, 0, \mathrm{u}}$ was set to 0.85, according to Hartnack [19] (Eq. 8).

$f_{\mathrm{c}, 0, \mathrm{u}}=\beta_{\mathrm{f}} \cdot f_{\mathrm{c}, 0}=0.85 \cdot f_{\mathrm{c}, 0}$

Numerical simulations were carried out on the buckling resistance of beech glulam columns. All columns were of strength class GL $48 \mathrm{~h}$ and had square cross-sections with a width of $b=200 \mathrm{~mm}$. The lamination thickness was $25 \mathrm{~mm}$, resulting in eight laminations per column. Buckling lengths of 720 , 1200, 1800, 2400, ..., $7200 \mathrm{~mm}$ were investigated.

A stochastic model for the board parameters density and dynamic MOE, previously developed by the authors [20], was used to generate physically plausible laminations. The parallel to the grain compressive strength $f_{\mathrm{c}, 0}$ and MOE $E_{\mathrm{c}, 0}$ of the generated boards were estimated using Eqs. 9 and 10 [20].

The generated boards were then combined into glulam columns (eight laminations per column). For each column length between 720 and $7200 \mathrm{~mm}, 100$ glulam columns were generated and simulations performed, i.e., columns with the same strength and stiffness properties were used in the simulations with different buckling lengths to make sure that the reduction in buckling resistance can only be caused by an increase of the slenderness ratio and not by differences related to the variability of mechanical properties.

In the simulations presented in this paper, the strain-based model ("model 1") presented by Theiler et al. [5, 14] was used. In this model, the buckling mode shape of the columns is predefined and averaged material parameters of the eight laminations are used. Given that during the tests buckling occurred with the laminations in edgewise bending, this simplification is deemed to be appropriate, since there is a homogenisation effect. The stress-strain relationship is determined based on these averaged material properties.

The force-deformation behaviour of each column can be estimated using the strain-based model and the predefined buckling mode shape. The force is continuously increased and, for each load step, the equilibrium stresses in the cross-section at mid-height are computed based on the deformed shape of the column. The maximum load carrying capacity is reached when 
the stresses in the cross-section are no longer able to balance the internal forces induced by the applied force [5]. Similar approaches, where strain-based models were applied to solve the equilibrium problem in the deformed state, were used by Blaß [3, 4], Roš and Brunner [21], Buchanan [22], and Hörsting [23].

\section{Results}

\subsection{Behaviour of stocky columns}

The compressive strengths determined in the experimental compression tests are summarised in Table 1 (top part), which also includes the cross-section widths (b), the buckling lengths $\left(L_{\mathrm{c}}\right)$, the slenderness ratios $(\lambda)$, and the numbers of tests per series $(n)$. The mean and 5\% fractile values were calculated assuming a lognormal distribution of the compressive strength [24].

For all tested configurations, the mean compressive strengths of the stocky columns were similar, i.e., no significant influence of the strength class, the crosssectional width, or the column length was found. The mean values of compressive strength were between 58.2 $\mathrm{MPa}(\mathrm{GL} \mathrm{48h,} b=280 \mathrm{~mm})$ and $65.8 \mathrm{MPa}(\mathrm{GL}$ $55 \mathrm{~h})$.

Within each tested configuration, the variation of strength values was quite low, with coefficients of variation (cov) below 0.04. Taking all series into account, a marked relationship between the compressive strength parallel to the grain and the density was observed (a fitted linear regression model shows a coefficient of determination $r^{2}=0.51$, which represents a medium correlation [24]). A linear regression model was fitted to describe the compressive strength parallel to the grain as a function of the basic parameters density (in $\mathrm{kg} / \mathrm{m}^{3}$ ) and dynamic MOE (in $\mathrm{MPa}$ ) of the boards (Eq. 9). It was assumed that the error term $\epsilon_{f_{\mathrm{c} .0}}$ was normal distributed. The mean value of the error term was $\mu=0$, the standard deviation of the error term was $\sigma=0.03$.

$$
\begin{aligned}
\ln \left(f_{\mathrm{c}, 0}\right)= & 2.61+1.45 \times 10^{-3} \cdot \rho+2.90 \times 10^{-5} \\
& \cdot E_{\mathrm{dyn}}+\epsilon_{f_{\mathrm{c}, 0}}
\end{aligned}
$$

Ductile failure behaviour was observed in the compression tests on stocky columns. The force-displacement curve was almost linear until a level of approximately $85 \%$ of the maximum force $F_{\max }$ (Fig. 5). The remaining $15 \%$ of the load-carrying capacity corresponded to about $30-40 \%$ of the total displacement at maximum force $F_{\max }$. Local crushing of wood fibres, frequently occuring near finger joints, knots or obvious fibre deviations, contributed to this ductile failure mechanism (Fig. 4).

The compressive MOE parallel to the grain determined in the experimental compression tests is presented in Table 1 (top part), which also includes the cross-section widths $(b)$, the buckling lengths $\left(L_{\mathrm{c}}\right)$, the slenderness ratios $(\lambda)$, and the numbers of tests per series $(n)$. The mean and $5 \%$ fractile values were calculated assuming a lognormal distribution of the compressive MOE parallel to the grain [24].

The mean compressive MOE parallel to the grain $\left(E_{\mathrm{c}, 0, \text { mean }}\right)$ was $15,100 \mathrm{MPa}$ for strength class GL $40 \mathrm{~h}$, $16,000 \mathrm{MPa}$ for GL $48 \mathrm{~h}$, and 17,000 MPa for GL 55h. These differences result from the strength grading procedure adopted, in which the dynamic MOE, a very good indicator of the static MOE, was a key grading parameter. As with the compressive strength, no influence of specimen length or cross-sectional area was observed in the compressive MOE parallel to the grain.

Taking all test series into account, the relationship between compressive MOE and density was analysed with a linear regression model, which showed a coefficient of determination of $r^{2}=0.43$. This corresponds to a medium/low correlation [24].

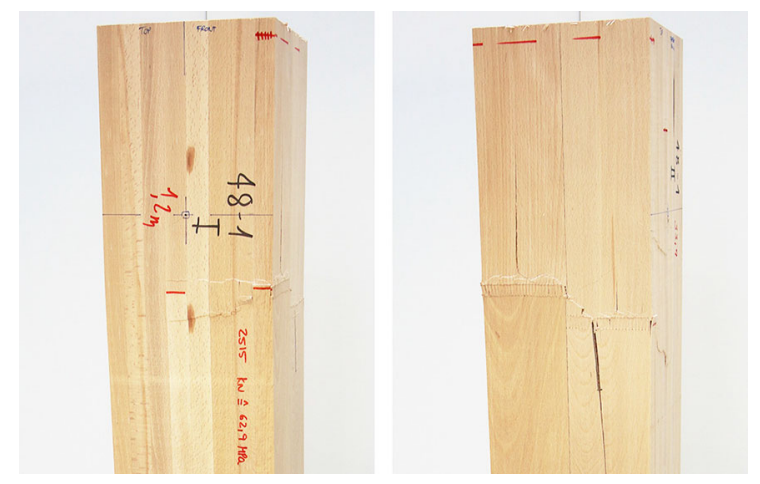

Fig. 4 Failure pattern in a stocky column of strength class GL $48 \mathrm{~h}$ after reaching a compressive strength of $f_{\mathrm{c}, 0}=62.9 \mathrm{MPa}$. Initial failure occured locally at finger joints 
Similar to the compressive strength, a linear regression model was fitted to describe the compressive MOE parallel to the grain as a function of the basic parameters density (in $\mathrm{kg} / \mathrm{m}^{3}$ ) and dynamic MOE (in MPa) of the boards (Eq. 10). It was assumed that the error term $\epsilon_{E_{\mathrm{c}, 0}}$ was normal distributed. The mean value of the error term was $\mu=0$, the standard deviation of the error term was $\sigma=0.04$.

$$
\ln \left(E_{\mathrm{c}, 0}\right)=8.67+5.80 \times 10^{-5} \cdot E_{\mathrm{dyn}}+\epsilon_{E_{\mathrm{c}, 0}}
$$

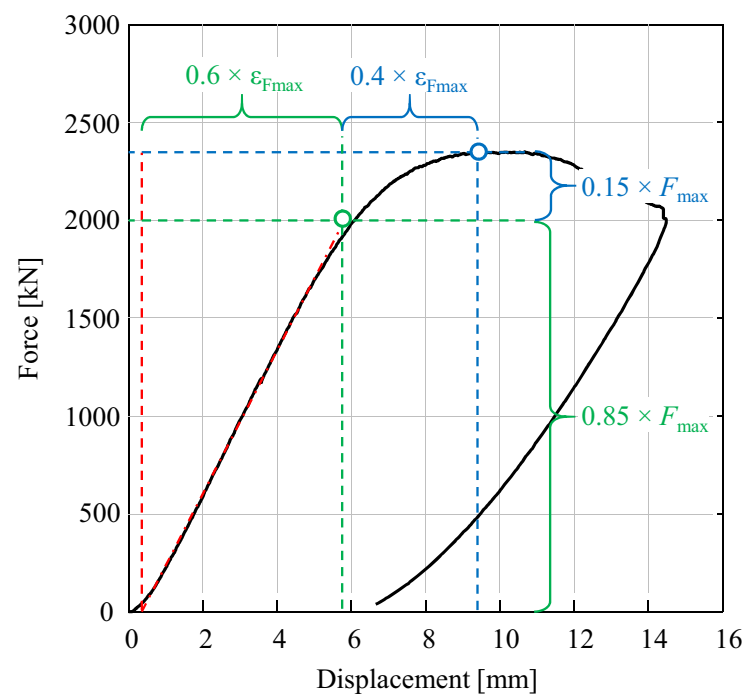

Fig. 5 Force-displacement behaviour of a stocky column (GL $40 \mathrm{~h}, b=200 \mathrm{~mm}, L=1200 \mathrm{~mm}$, no. 3). After a phase of linear-elastic behaviour, local crushing of wood fibres caused plastic deformations and led to a ductile failure behaviour

\subsection{Behaviour of slender columns}

The columns with higher slenderness ratios of $\lambda=$ $41.5\left(L_{\mathrm{c}}=2400 \mathrm{~mm}\right)$ and $\lambda=62.3\left(L_{\mathrm{c}}=3600 \mathrm{~mm}\right)$ exhibited a significant decrease in load-carrying capacity (Table 1, bottom part). Compared to the overall mean compressive strength of the stocky columns of strength class GL $48 \mathrm{~h}(60.6 \mathrm{MPa}=$ $100 \%)$, the nominal compressive strength reached in the slender columns was only $45.3 \mathrm{MPa}(\lambda=41.5$, $74.8 \%)$ and $30.5 \mathrm{MPa}(\lambda=62.3,50.3 \%)$. In the strength class GL $40 \mathrm{~h}$, the reduction was similar.

Table 1 (bottom part) summarises the compressive MOE parallel to the grain determined in the buckling tests. Compared to the results of the stocky columns (GL 40h: $E_{\mathrm{c}, 0 \text {,mean }}=15,100 \mathrm{MPa}$; GL 48h: $E_{\mathrm{c}, 0, \text { mean }}=$ $16,000 \mathrm{MPa}$ ), mean values for the MOE parallel to the grain of the slender columns were on a very similar level (GL 40h: $E_{\mathrm{c}, 0, \text { mean }}=14,900 \mathrm{MPa}$; GL 48h: $\left.E_{\mathrm{c}, 0, \text { mean }}=16,400 \mathrm{MPa}\right)$.

Figure 6 shows the longitudinal deformations measured at the centre of the "compression" ( $v_{1}$ and $\left.v_{2}\right)$, "tension" ( $v_{3}$ and $\left.v_{4}\right)$ and "bending" ( $v_{5}$ and $\left.v_{6}\right)$ faces, as a function of the applied force, for buckling lengths of $2400 \mathrm{~mm}$ (a) and $3600 \mathrm{~mm}$ (b). The deformations were measured at mid-height of the columns over lengths of $600 \mathrm{~mm}$. The initial behaviour is linear elastic. When the applied force was approaching the buckling force, the less slender columns (buckling length of $2400 \mathrm{~mm}$ ) did not exhibit elongations on the tension side (Fig. 6a), which shows that the entire cross-section was subjected to compressive stresses (Fig. 7a).
Fig. 6 Typical forcedisplacement curves determined in buckling tests on columns: a buckling length of $2400 \mathrm{~mm}$; b buckling length of 3600 $\mathrm{mm}$. The displacements were measured over a length of $600 \mathrm{~mm}$ at mid-height of the column on the compression ( $v_{1}$ and $v_{2}$ ), tension $\left(v_{3}\right.$ and $\left.v_{4}\right)$, and bending sides ( $v_{5}$ and $v_{6}$ )
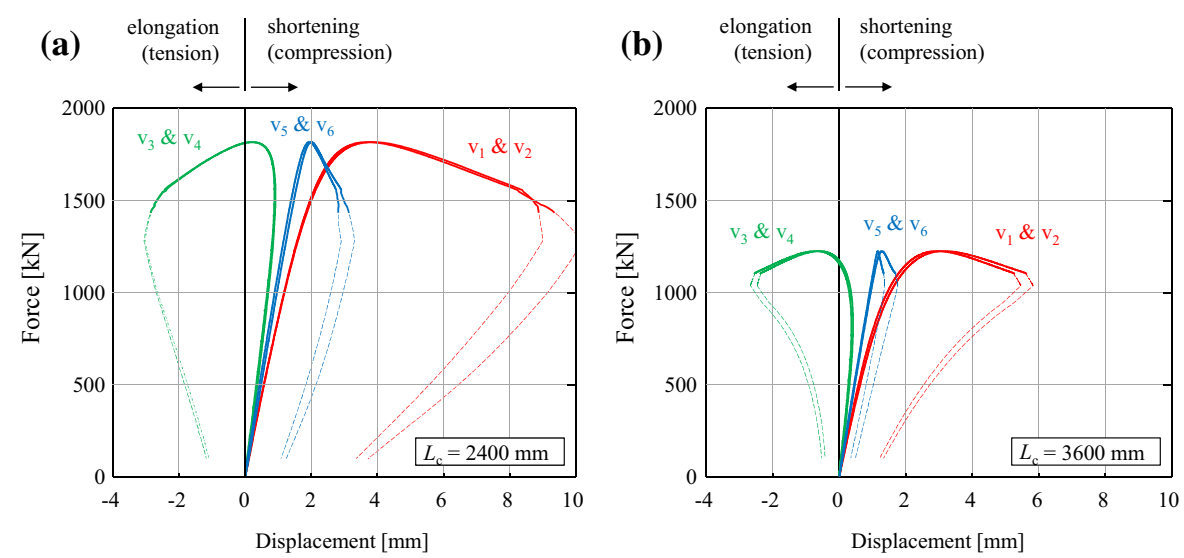
Fig. 7 Strains on the compression ( $v_{1}$ and $v_{2}$ ), tension $\left(v_{3}\right.$ and $\left.v_{4}\right)$, and bending surfaces $\left(v_{5}\right.$ and $\left.v_{6}\right)$ when the buckling force was reached: $\mathbf{a}$ in the columns with a buckling length of $2400 \mathrm{~mm}$, shortening was observed in the whole crosssection $\left(\epsilon_{\mathrm{i}} \geq 0\right)$, showing that only compressive stresses are present; $\mathbf{b}$ in the columns with a buckling length of $3600 \mathrm{~mm}$, elongation was observed on the tensile side, showing that tensile stresses occured in parts of the cross-section

Fig. 8 Experimental and simulated compressive strengths for columns of strength class GL $48 \mathrm{~h}$ and different slenderness ratios $\lambda$. Design according to Eurocode 5 [1]

$\left(\beta_{\mathrm{c}}=0.10, \lambda_{\text {rel }, 0}=0.30\right)$ leads to an overestimation of the compressive strength by up to $18 \%$. A better fit with the experimental and simulation results is reached by changing the parameters to $\beta_{\mathrm{c}}=0.25$ and $\lambda_{\text {rel }, 0}=0.25$ (a)

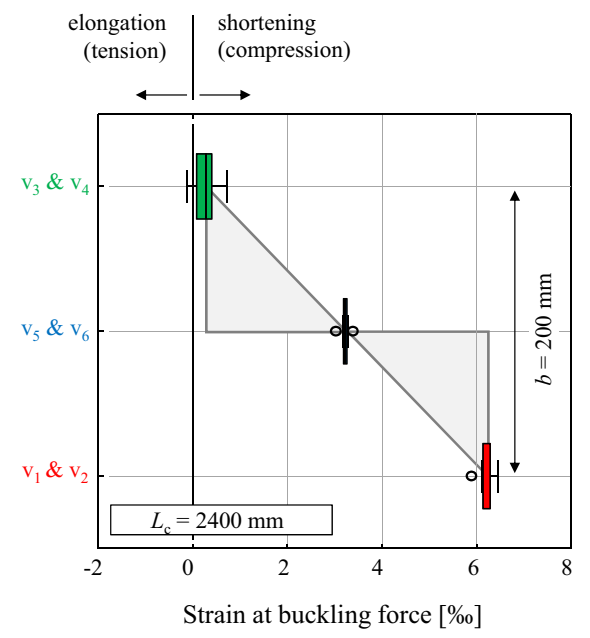

(b)
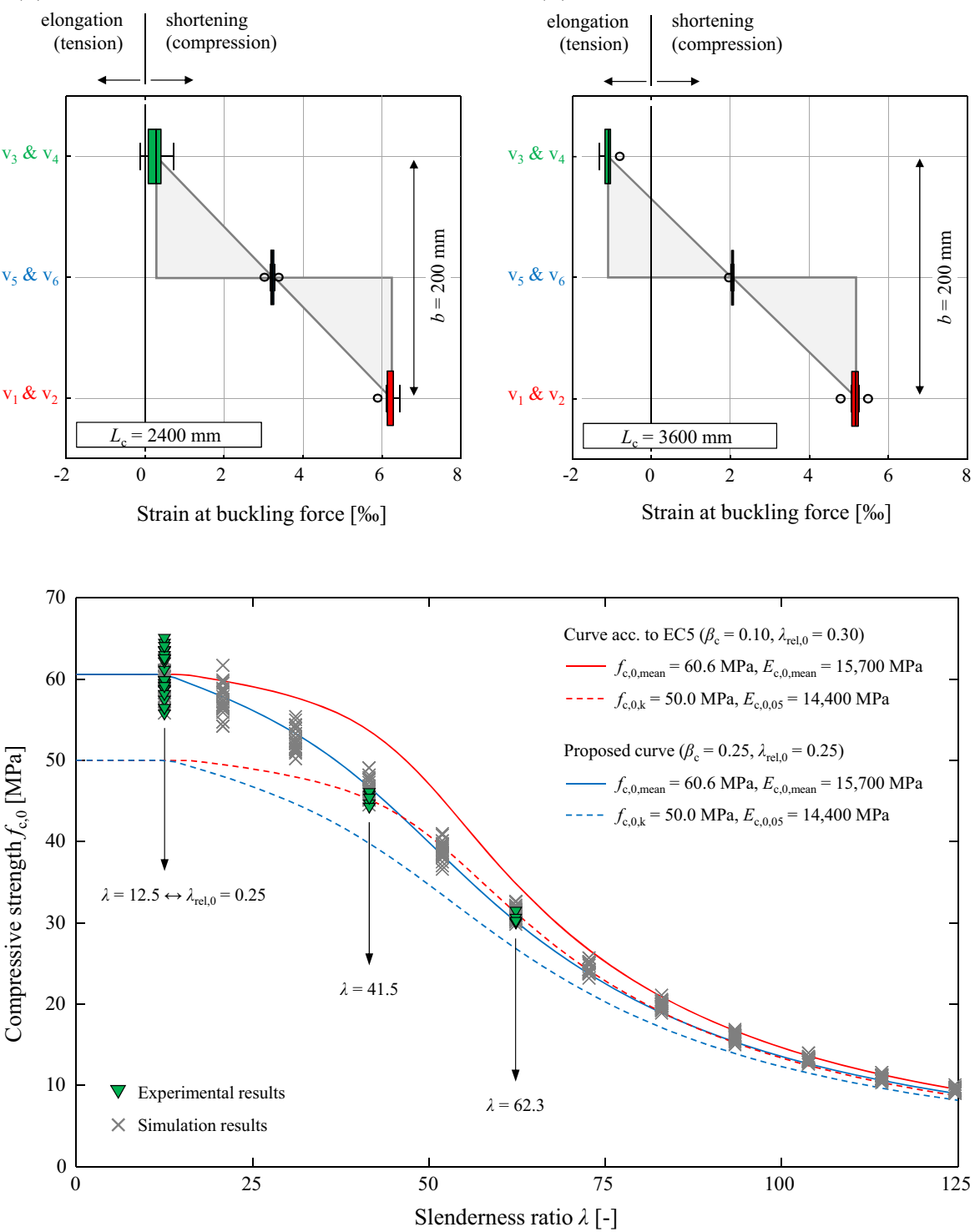

With the more slender columns (buckling length of $3600 \mathrm{~mm}$ ), elongations appeared on the tension side shortly before the buckling force was reached (Fig. 6b), showing that tensile stresses were present in parts of the column's cross-section (Fig. 7b). The average strain recorded on the compression side at the level of maximum (buckling) force was $6.21 \%$ for buckling length $2400 \mathrm{~mm}$ (Fig. 7a) and $5.16 \%$ for buckling length $3600 \mathrm{~mm}$ (Fig. 7b).

\subsection{Applicability of the effective-length-method} to the design of European beech glulam columns

The compressive strengths of the stocky columns $(\lambda=$ 12.5) and the nominal compressive strengths of the slender columns $(\lambda=41.5$ and 62.3$)$ are plotted in Fig. 8 (triangles). The results of the simulations on the generated columns (see Sect. 2.3) are also graphed in Fig. 8 (crosses).

The compressive strengths obtained from the simulations agree well with the experimental data. 
For $\lambda=12.5$, the simulation results lead to values $2 \%$ lower than the experimental results on average. For the slenderness ratios $\lambda=41.5$ and $\lambda=62.3$, the simulation results are $3 \%$ and $2 \%$ higher than the experimental results on average. The differences for $\lambda=41.5$ are partly to be attributed to the larger eccentricity in the experimental tests compared to the simulations $(L / 380$ vs. $L / 500)$. The disparities regarding the eccentricities in the tests and simulations are due to differences between the planned and the actual measured eccentricities in the tests.

The Eurocode 5 [1] design approach used for the verification of the stability of columns under compression is described by the Eqs. 11-14. The instability factor (or buckling coefficient) $k_{\mathrm{c}}$ is calculated based on the relative slenderness ratio $\lambda_{\text {rel }}$ and the factor $k$, which is a function of the critical relative slenderness ratio $\lambda_{\text {rel }, 0}$ and the straightness factor $\beta_{\mathrm{c}}$. The critical relative slenderness represents the slenderness level above which buckling has to be considered in design. The straightness factor describes the slope of the buckling curve after that point.

$$
\begin{aligned}
& \sigma_{\mathrm{c}, 0, \mathrm{~d}} \leq k_{\mathrm{c}} \cdot f_{\mathrm{c}, 0, \mathrm{~d}} \\
& k_{\mathrm{c}}=\frac{1}{k+\sqrt{k^{2}-\lambda_{\text {rel }}^{2}}} \\
& k=0.5 \cdot\left[1+\beta_{\mathrm{c}} \cdot\left(\lambda_{\mathrm{rel}}-\lambda_{\mathrm{rel}, 0}\right)+\lambda_{\mathrm{rel}}^{2}\right] \\
& \lambda_{\text {rel }}=\frac{\lambda}{\pi} \cdot \sqrt{\frac{f_{\mathrm{c}, 0, \mathrm{k}}}{E_{\mathrm{c}, 0,05}}}
\end{aligned}
$$

The values $\lambda_{\text {rel }, 0}=0.3$ and $\beta \mathrm{c}=0.1$ specified in Eurocode 5 [1] are based on investigations on softwood glulam by Blaß [3, 4]. However, in the case of beech glulam, these values lead to unsafe estimates of the buckling resistance of columns, as shown in Fig. 8. If the mean values for compressive strength parallel to the grain and the MOE parallel to the grain experimentally determined for GL $48 \mathrm{~h}$ $\left(f_{\mathrm{c}, 0 \text {, mean }}=60.6 \mathrm{MPa}, E_{\mathrm{c}, 0 \text {, mean }}=15,700 \mathrm{MPa}\right)$ are used in Eq. 14, which is appropriate for comparison with test results, the curve according to Eurocode 5 [1] overestimates the (mean) experimental and simulation results by up to $18 \%$ (Fig. 8). Even when using the $5 \%$-fractile value for the MOE $E_{\mathrm{c}, 0,05}=14,400 \mathrm{MPa}$ and the rather conservative $5 \%$-fractile value for
Table 2 Compressive strength and MOE parallel to the grain of beech glulam determined by Ehrhart [20] for strength classes GL 40h, GL 48h, and GL 55h

\begin{tabular}{lllll}
\hline Property & Unit & GL 40h & GL 48h & GL 55h \\
\hline$f_{\mathrm{c}, 0, \mathrm{~g}, \mathrm{k}}$ & $\mathrm{MPa}$ & 45.0 & 50.0 & 55.0 \\
$E_{\mathrm{c}, 0, \mathrm{~g}, \text { mean }}$ & $\mathrm{MPa}$ & 14,200 & 15,400 & 16,600 \\
$E_{\mathrm{c}, 0, \mathrm{~g}, \mathrm{k}}$ & $\mathrm{MPa}$ & 13,200 & 14,400 & 15,600 \\
\hline
\end{tabular}

compressive strength $f_{\mathrm{c}, 0, \mathrm{k}}=50.0 \mathrm{MPa}$, determined by Ehrhart [20] (Table 2), the design curve according to Eurocode 5 [1] unsafely overestimates the mean experimental and simulation results for slenderness ratios $\lambda \geq 45$ (Fig. 8).

On the one hand, the differences between the test results and design according to Eurocode 5 [1] are due to the different ratios between compressive strength and MOE parallel to the grain between softwood glulam and beech glulam. Ratios of $f_{\mathrm{c}, 0} / E_{\mathrm{c}, 0}$ between $1 / 370$ and $1 / 420$ are reported for softwood glulam [3], ratios of about $f_{\mathrm{c}, 0} / E_{\mathrm{c}, 0}=1 / 250$ have been found for beech glulam $[8,9]$. Since the values of $\lambda_{\text {rel }, 0}$ and $\beta_{\mathrm{c}}$ adopted in Eurocode 5 [1] are based on research on softwood, disparities between the Eurocode 5 [1] predictions and the experimental results for beech glulam were expected.

On the other hand, however, the fact that design according to Eurocode 5 [1] leads to a significant overestimation of the buckling resistance is due to the differences regarding the assumptions related to relevant material properties and imperfections. The buckling resistance of columns is predominantly influenced by (1) the compressive strength, (2) the MOE parallel to the grain, and (3) the structural and geometrical imperfections. The buckling resistances found in this study for European beech glulam columns represent the buckling behaviour of columns with (1) $5 \%$-fractile values of the compressive strength, (2) $5 \%$-fractile values of the MOE-both determined according to EN 408 [12] - and (3) a geometrical imperfection of $e=L / 500$ as specified in Eurocode 5 [1] to be the maximum geometrical imperfection permitted.

In contrast, the buckling curves in Eurocode 5 [1] represent the $5 \%$-fractile value of the buckling resistance, i.e., the columns either have a low compressive 
strength, a low MOE parallel to the grain, or an imperfection close to the maximum limit $e=L / 500$. The eccentricities used in the simulations by Blaß [3] were predominantly markedly below the maximum limit of $L / 500$ defined in Eurocode 5 [1]. Based on measurements of the imperfections of 176 timber columns in 13 buildings [25, 26], Blaß [3] assumed that the geometrical imperfections due to curvature of the columns were normally distributed with a mean value of eccentricity of $\left(\mu_{\mathrm{e}}=\right) 1.40 \times 10^{-5} \times L$ and a standard deviation of $\left(\sigma_{\mathrm{e}}=\right) 4.53 \times 10^{-4} \times L$. Hence, in about $95 \%$ of the simulations, imperfections due to curvature were below $L / 1100$ and in about $80 \%$ of the simulations, imperfections due to curvature were below $L / 1700$. Additional imperfections regarding the eccentricity of the load application were not considered in the simulations.

Based on the experimental and numerical investiagions, a critical relative slenderness ratio $\lambda_{\text {rel }, 0}=$ 0.25 and a straightness factor $\beta_{\mathrm{c}}=0.25$ are proposed for the verification of beech glulam columns subjected to axial compression instead of the current values prescribed in Eurocode 5 [1] $\quad\left(\lambda_{\text {rel }, 0}=0.30\right.$; $\left.\beta_{\mathrm{c}}=0.10\right)$. Taking into account that the test specimen for determining the compressive strength in accordance with EN 408 [12] has a slenderness ratio of $\lambda=(0.6 \times 6 \times b) /(0.289 \times b)$ and that $f_{\mathrm{c}, 0} / E_{\mathrm{c}, 0}=$ $1 / 250$ for beech glulam, a critical relative slenderness ratio $\lambda_{\text {rel }, 0}=0.25$ is obtained (Eq. 14). Buckling phenomena below this threshold are therefore included in the compressive strength determined in accordance with the standard EN 408 [12], which justifies a sharp bend in the buckling curve.

The imperfection coefficient $\beta_{\mathrm{c}}$, which describes the slope of the buckling curve, was calibrated based on the experimental and simulation results. A value of 0.25 leads to a buckling curve that fits well to the mean values of the experimental and simulation results (Fig. 8). If the $5 \%$-fractile values of $f_{\mathrm{c}, 0}$ and $E_{\mathrm{c}, 0}$ determined by Ehrhart [20] (Table 2) are used with the proposed $\lambda_{\text {rel }, 0}$ and $\beta_{\mathrm{c}}$ parameters, the ELM can be safely applied to verify the stability of beech glulam columns of strength classes GL 40h, GL 48h and GL $55 \mathrm{~h}$ subjected to axial compression. In any case, the determination of buckling design curves for softwood and beech glulam columns should be based on the same assumptions, especially regarding the considered imperfections.

\section{Conclusions}

The current Eurocode 5 design rules based on the effective-length method for verifying the stability of columns subjected to axial compression do not allow to accurately predict the buckling resistance of glulam columns made of European beech (Fagus sylvatica L.) wood.

Full scale experiments on columns with lengths of $2400 \mathrm{~mm}(\lambda=41.5)$ and $3600 \mathrm{~mm}(\lambda=62.3)$, which were accompanied by numerical investigations, have shown that the parameters $\lambda_{\text {rel }, 0}=0.30$ and $\beta_{\mathrm{c}}=0.10$ currently specified in Eurocode 5 [1] for softwood glulam lead to an overestimation of the compressive strength of up to $18 \%$ in case of beech glulam columns.

Best fitting the experimental and numerical results, a critical relative slenderness ratio of $\lambda_{\text {rel }, 0}=0.25$, which defines the level of relative slenderness above which buckling has to be considered in the design, and an imperfection coefficient of $\beta_{\mathrm{c}}=0.25$ are proposed. These values are considered to assure that the effective-length method can be safely applied to verify the stability of beech glulam columns of strength classes GL 40h, GL 48h and GL 55h subjected to axial compression.

The significant differences between the buckling curves resulting from this study and the design according to Eurocode 5 [1] are mainly due to different assumptions regarding the material properties and imperfections. While in this study the buckling curves were defined based on 5\%-fractile values for strength and stiffness and an eccentricity of $L / 500$, the curves according to Eurocode 5 [1] are valid for columns where either the stiffness or the strength is at $5 \%$ level, the other value is at the mean level and the eccentricity is significantly below the maximum value permitted by Eurocode 5 [1] of $L / 500$. In any case, the determination of buckling design curves for softwood and beech glulam columns should be based on the same assumptions, especially regarding the considered imperfections.

Acknowledgements Open access funding provided by Empa Swiss Federal Laboratories for Materials Science and Technology. The authors gratefully acknowledge the financial support received from the Swiss Federal Office for the Environment in the framework of the Aktionsplan Holz. The authors would also like to acknowledge the valuable collaboration with the sawmills Corbat SA, Konrad Keller 
$A G$, Richard Lötscher $A G$, and Koller $A G$, and the contribution of the suppliers of the strength grading devices MiCROTEC and Brookhuis as well as of the adhesive experts of Henkel Engineered Wood Adhesives. Finally, the assistance of the technicians at Empa in preparing and carrying out the experiments as well as the input and support by Holzindustrie Schweiz, the hardwood glulam specialists of neue Holzbau AG, who took care of producing the glulam specimens, and the experts Prof. em. E. Gehri and M. Zimmermann are thankfully acknowledged.

Funding This study was funded by the Swiss Federal Office for the Environment (FOEN) within the framework of the Aktionsplan Holz. This study was also supported by Bundesamt für Umwelt (Grant No. REF-1011-04200).

\section{Compliance with ethical standards}

Conflict of Interest The authors declare that they have no conflict of interest.

Open Access This article is licensed under a Creative Commons Attribution 4.0 International License, which permits use, sharing, adaptation, distribution and reproduction in any medium or format, as long as you give appropriate credit to the original author(s) and the source, provide a link to the Creative Commons licence, and indicate if changes were made. The images or other third party material in this article are included in the article's Creative Commons licence, unless indicated otherwise in a credit line to the material. If material is not included in the article's Creative Commons licence and your intended use is not permitted by statutory regulation or exceeds the permitted use, you will need to obtain permission directly from the copyright holder. To view a copy of this licence, visit http://creativecommons.org/licenses/by/4.0/.

\section{References}

1. EN 1995-1-1 (2010) Design of timber structures-part 1-1: general-common rules and rules for buildings. CEN European Committee for Standardization, Brussels

2. EN 1993-1-1 (2010) Design of steel structures-part 1-1: general rules and rules for buildings. CEN European Committee for Standardization, Brussels

3. Blaß HJ (1987) Tragfähigkeit von Druckstäben aus Brettschichtholz unter Berücksichtigung streuender Einflussgrössen. Dissertation, University Fridericiana Karlsruhe, Karlsruhe, Germany

4. Blaß HJ (1987) Design of timber columns, paper 20-2-2. CIB-Meeting Twenty, Dublin, Ireland

5. Theiler M (2014) Stabilität von axial auf Druck beanspruchten Bauteilen aus Vollholz und Brettschichtholz. Dissertation, ETH Zürich, Zurich, Switzerland

6. Estévez Cimadevilla J, Otero Chans D, Martín Gutiérrez E, Vázquez Rodríguez J (2013) Experimental analysis of glued-laminated timber bars with box section used in the construction of a spatial grid. Maderas. Ciencia y tecnología 15(2):153-170
7. Fleming PH, Ramage MH (2020) Full-scale construction and testing of stress-laminated columns made with lowgrade wood. Constr Build Mater 230:116952

8. Ehrhart T, Steiger R, Palma P, Frangi A (2018) Mechanical properties of European beech (Fagus sylvatica L.) glued laminated timber. Paper 51-12-4. International network on timber engineering research INTER-meeting fifty-one. Tallinn, Estonia, pp 343-360

9. Westermayr M, Stapel P, Van de Kuilen JWG (2018) Tensile and compression strength of small cross-section beech glulam members. Paper 51-12-2. International network on timber engineering research INTER-meeting fifty-one. Tallinn, Estonia, pp 307-322

10. Ehrhart T, Fink G, Steiger R, Frangi A (2015) Strength grading of European beech lamellas for the production of GLT and CLT. Paper 49-5-1. International network on timber engineering research INTER - meeting forty-nine. Graz, Austria, pp 29-43

11. Lehmann M, Clerc G, Lehringer C, Strahm T, Volkmer T (2018) Investigation of the bond quality and the finger joint strength of beech glulam. In: World conference on timber engineering 2018. Seoul, Republic of Korea

12. EN 408 (2012) Timber structures - structural timber and glued laminated timber-determination of some physical and mechanical properties. CEN European Committee for Standardization, Brussels

13. von Tetmajer L (1888) Zur Frage der Knickfestigkeit der Bauhölzer. Schweizerische Bauzeitung 17(11/12):110-113

14. Theiler M, Frangi A, Steiger R (2012) Design of timber columns based on 2nd order structural analysis. Paper 45-21. CIB - meeting forty five. Växjö, Sweden, pp 81-96

15. Frangi A, Theiler M, Steiger R (2015) Design of timber members subjected to axial compression or combined axial compression and bending based on 2nd order theory. Paper 48-2-2. CIB-meeting forty eight. Šibenik, Croatia, pp 45-60

16. Glos P (1978) Zur Bestimmung des Festigkeitsverhaltens von Brettschichtholz bei Druckbeanspruchung aus Werkstoff- und Einwirkungsgrössen. Dissertation, TU Munich, Munich, Germany

17. Glos P, Denzler JK, Linsenmann P (2004) Strength and stiffness behaviour of beech laminations for high strength glulam. Paper 37-6-3. CIB-meeting thirty-seven. Edinburgh, Scotland

18. O'Halloran MR (1973) Curvilinear stress-strain relationship for wood in compression. Dissertation, Colorado State University, Fort Collins, US

19. Hartnack R (2004) Langzeitverhalten von druckbeanspruchten Bauteilen aus Holz. Dissertation, BauhausUniversität Weimar, Weimar, Germany

20. Ehrhart T (2019) European beech glued laminated timber. Dissertation, ETH Zürich, Zurich, Switzerland

21. Roš M, Brunner J (1931) Die Knickfestigkeit der Bauhölzer. Kongress des internationalen Verbandes für Materialprüfung, Zurich, Switzerland

22. Buchanan A (1984) Strength model and design methods for bending and axial load interaction in timber members. Dissertation, University of British Columbia, Vancouver, Canada 
23. Hörsting OP (2008) Zum Tragverhalten druck- und biegebeanspruchter Holzbauteile. Dissertation, TU Braunschweig, Braunschweig, Germany

24. JCSS Probabilistic Model Code (2006) Part 3-resistance models. ISBN 978-3-909386-79-6

25. Ehlbeck J, Blaß HJ (1987) Zuverlässigkeit von Holzdruckstäben. Bauforschung, Report T 1984, Fraunhofer IRB Verlag
26. Ehlbeck J, Blaß HJ (1987) Imperfektionsannahmen für Holzdruckstäbe. Holz als Roh- und Werkstoff 45:231-235

Publisher's Note Springer Nature remains neutral with regard to jurisdictional claims in published maps and institutional affiliations. 